\title{
Percepción de los estudiantes tutorados sobre el programa de tutores pares y su relación con el desempeño académico: evidencia desde el norte de Chile
}

\author{
Carmen A. Araneda-Guirriman*, Andrea F. Obregón, Patrick A. Pérez y David A. Catari-Vargas \\ Departamento de Ingeniería Industrial y de Sistemas, Facultad de Ingeniería, Universidad de Tarapacá, Casilla 6D, \\ Arica-Chile. (correo-e: caraneda@uta.cl, andrea.obregoncampillay@gmail.com; patrickperezsalgado@gmail.com; \\ dacatari@uta.cl)
}

* Autor a quien debe ser dirigida la correspondencia.

Recibido Jul. 19, 2019; Aceptado Sep. 12, 2019; Versión final Ene. 2, 2020, Publicado Jun. 2020

\begin{abstract}
Resumen
El presente artículo tiene por propósito mostrar la relación entre la percepción de las dimensiones del Programa de Tutores Pares y el desempeño académico de los estudiantes que en su primer año universitario participaron en este programa. Se realizó un estudio de caso de corte cuantitativo en una universidad estatal del extremo norte de Chile. Se desarrolló y validó un cuestionario que mide las siguientes dimensiones del programa: información entregada, apoyo brindado, infraestructura utilizada y el rol del tutor. Los datos se procesaron a través de un análisis estadístico bivariado de Chi cuadrado y Correlaciones de Pearson. Los resultados indican que existe una relación estadísticamente significativa entre el apoyo brindado, el rol del tutor y el desempeño académico de los tutorados en su primer año universitario. En consecuencia, se destacan en importancia el apoyo que este programa brinda a los estudiantes y el tutor que ejecuta finalmente el programa.
\end{abstract}

Palabras clave: programa de tutores pares; desempeño académico; educación superior; estudiantes; primer año de universidad

\section{Perception of tutored students in the peer tutors program and its relation to academic performance: evidence from northern Chile}

\begin{abstract}
The purpose of this study is to show the relationship between the perception of the dimensions of the Peer Tutoring Program and student academic performance that participated in this program in their first year at university. A quantitative cut case study was conducted in a state university in the north of Chile. For this purpose it was developed and validated a questionnaire that measures the following aspects of the tutoring program: information provided, support provided, infrastructure used, and the tutor's role. The data were processed using Chi square bivariate statistical analysis and Pearson correlations. The results indicated that there was a statistically significant relationship between support provided, the tutor's role, and the tutor's academic performance in their first year at university. This highlights the importance that the support of the Peer Tutoring Program provides for the students and tutors that execute the program.
\end{abstract}




\section{INTRODUCCIÓN}

Los sistemas de educación superior han experimentado un acelerado proceso de expansión alrededor del mundo que ha afectado no solo los países de ingresos medios, sino que también los países de bajos ingresos quienes han evidenciado su masificación en el acceso (Rizvi, 2018). En este ámbito, el acceso a la educación superior marca una expansión sin precedentes con aproximadamente de 134 millones de estudiantes matriculados en la educación postsecundaria alrededor del mundo (Altbach, 2015). Como parte de este proceso de expansión y heterogenización se tiene la presencia de un nuevo grupo de estudiantes, quienes producto de un complejo entramado de factores sociales, económicos y culturales estuvo inicialmente excluido de la educación superior y hoy en día han incrementado su participación (Schuetze y Slowey, 2002). Esto ha implicado cambios en la demografía del cuerpo de estudiantes desafiando la noción de "estudiante" tan central en el imaginario político (Trowler, 2019). Por consiguiente, esta ampliación de las iniciativas de participación en la educación terciaria necesita ser cuidadosamente considerada y asociada a su vez con las agendas de justicia social referidas al acceso y la equidad (O'Shea, 2016).

En este contexto, los estudiantes que recién comienzan sus estudios superiores están por experimentar diversos cambios o transiciones que los llevan a vivir una amplia gama de nuevas experiencias (Bowles et al., 2014). La transición de los estudiantes a la vida universitaria es una preocupación, más aún cuando se aborda la deserción estudiantil en la educación superior, razón por la cual, existen numerosos esquemas para incrementar la retención estudiantil, generalmente con foco e $\mathrm{n}$ los grupos no tradicionales (Cotton et al., 2017). Lo anterior debido a que la transición a la educación superior es un proceso complejo de cambios, resistencia, reposicionamiento y construcción subjetiva, por tanto, donde no solo se construye la identidad de estudiante, sino que considera además las prácticas particulares y las formas de hacer las cosas al interior de un contexto cultural particular para que el sujeto pueda ser reconocido como estudiante (Scott, 2014). A este respecto, se debe reconocer además que la heterogeneidad entre los estudiantes se traduce en diferentes demandas y requisitos que estructuran la experiencia de pertenencia (Trowler, 2019). Esta heterogeneidad en la población de estudiantes universitarios se caracteriza por la presencia de individuos que son padres o madres, de mayor edad, pertenecientes a los grupos de menores ingresos en la sociedad, de las clases trabajadoras, de minorías y pertenecientes a una primera generación en sus familias en acceder a la educación superior (Araneda-Guirriman et al., 2018; Holton, 2017).

El programa de tutores pares para los estudiantes de pregrado se configura entonces como una ayuda para los diversos estudiantes en su transición de la educación secundaria a la educación superior (Cutright y Evans, 2016), puesto que es una iniciativa caracterizada por tener a un estudiante de curso más avanzado apoyando a estudiantes que están en niveles inferiores (Colvin, 2015). En Chile, desde el año 2008 se comenzó a aplicar dentro de los modelos educativos el programa de tutorías pares (Díaz y Morrison, 2016). Esto con la finalidad de disminuir significativamente la problemática del abandono en la educación superior y conseguir a su vez una mayor adaptación al proceso de transición a la vida universitaria del cual se hacen partícipes los nuevos estudiantes. De esta forma los servicios dirigidos a los estudiantes universitarios incluyen una alta gama de actividades, por ejemplo, tutorías, tutoría formal y programas integrales. Todos ellos valorados como efectivos para promover el logro académico cuando se implementan de manera coordinada y se asegura la calidad en el servicio (Mayhew et al., 2016). Por lo tanto, para apoyar la transición a la vida universitaria, las instituciones de educación superior han implementado el programa de tutorías entre pares, entre otras medidas, para enfrentar de manera exitosa la transición a la educación superior y evitar así la deserción al aproximar a los estudiantes a la vida universitaria con el apoyo de otros estudiantes.

El presente estudio, por consiguiente, aborda al programa de tutores pares de una Universidad del Norte de Chile con la finalidad de conocer la percepción de los estudiantes tutorados que participaron en este programa respecto a las dimensiones que lo componen, es decir información, apoyo, infraestructura y tutor con el objetivo de describir si existe una relación estadísticamente significativa entre esta percepción y su desempeño académico durante el primer año de universidad. De esta forma se tiene una aproximación del rol que tiene el programa de tutores pares en la transición a la vida universitaria de los estudiantes, y su relación con el desempeño académico durante el primer año de universidad.

\section{OTROS ANTECEDENTES}

Es conveniente detallar algunos aspectos del marco conceptual de este estudio, el que se presenta en dos subsecciones: una se refiere a la educación superior y su contexto y la otra a los programas de tutores pares.

\section{Educación Superior y su Contexto}

La masificación de la educación superior alrededor del mundo se configura como un proceso transformador que afecta a las sociedades en su conjunto y se está convirtiendo en un hecho casi universal, situación que es iniciada y regulada por los Estados, en cuyo contexto los graduados son además absorbidos en mayor o menor medida por las economías nacionales y globales (Marginson, 2016). 
No obstante, a pesar del incremento en el número de estudiantes que accede a la educación superior , su crecimiento ha sido proporcionalmente menor en los países de bajos ingresos como ocurre por ejemplo en la región de África Subsahariana, la cual tiene la tasa de participación más baja de educación superior en el mundo (6\%) (Unterhalter, 2017). En promedio, de los países de la OCDE, el 66\% de los adultos jóvenes entrarán en la educación superior por primera vez en su vida si los patrones de ingreso se mantienen, en este sentido, Chile (89\%), Dinamarca (86\%) y Nueva Zelanda (91\%) han tenido las tasas más altas de ingreso por primera vez a la educación superior del total de países que forman parte de esta organización (OECD, 2018). América Latina también ha masificado su sistema de educación superior, específicamente al inicio del siglo XXI se dio la mayor expansión de la educación terciaria, sin embargo, esta expansión de la matrícula universitaria viene siendo desigual, puesto que la participación de los jóvenes continúa siendo determinada según residencia, situación económica o etnicidad, lo cual demuestra lo limitado de la democratización universitaria (Cuenca, 2018).

Esta expansión de la educación superior y su consecuente diversificación del perfil de estudiantes que acceden tiene otras problemáticas asociadas, como lo son la retención y la deserción. En este sentido, se observa que en las universidades chilenas la tasa de retención de primer año para programas regulares de pregrado para la cohorte 2017 corresponde al 78,7\%, donde las universidades acreditadas tienen una mayor retención de primer año con una tasa de $73,3 \%$ y las no acreditadas con un $56,6 \%$ (SIES, 2018). Un estudio para predecir la deserción de los estudiantes universitarios de una universidad pública chilena en este ámbito indica que las variables claves para determinar la deserción son el promedio de notas, los años de avance en la carrera y el puntaje en la prueba de selección universitaria (Ramírez y Grandón, 2018).

Cabe precisar con respecto a la utilización del término de deserción existen iniciativas como el proyecto Alfa Guía (2013) que han promovido el uso del concepto de abandono en reemplazo de deserción, puesto que este concepto tiene una connotación negativa que resalta la responsabilidad del estudiante, sin considerar el impacto de los factores estructurales. En esta línea, García et al., (2016) hacen referencia a 5 factores asociados al fenómeno del abandono en la educación superior, los cuales son los individuales, académicos, económicos, institucionales, así como también aspectos relacionados con los estudiantes, o la interacción de los estudiantes en ciertos contextos. No obstante, los resultados de un estudio efectuado por Munizaga et al., (2018) indican que, a pesar de los esfuerzos por posicionar el término de abandono estudiantil, continúa siendo más utilizado el concepto de deserción.

La educación superior en Chile entre los años 2004 y 2014 experimentó un incremento del 78,6\% en el número de estudiantes con un fuerte aumento de los estudiantes provenientes de los sectores desfavorecidos de la sociedad. A pesar de este incremento sostenido en el acceso a la educación terciaria persisten las altas tasa de deserción, pues el ingreso a la educación superior no garantiza que los estudiantes finalicen exitosamente sus estudios, con una tasa de graduación del 33\% para el año 2014 que está por debajo del promedio de la OCDE del $36 \%$. Esto refleja las dificultades que experimentan los estudiantes para transitar de la educación media a la educación superior (OCDE, 2017). De acuerdo con un estudio efectuado por Eckert y Suénaga (2015) se identificaron que durante el primer año de carrera adquieren relevancia las acciones de contención, apoyo, tutoría, entre otras acciones que contribuyan a mejorar la situación académica del estudiante en la universidad. En este ámbito, el factor académico considerado en el análisis del abandono de la educación superior devela el rol de las universidades, es decir, la relevancia que tienen las intervenciones que se efectúan al interior de estas instituciones con el fin de lograr una adaptación a la vida universitaria (Munizaga et al., 2018). Al mismo tiempo, resulta necesario para las universidades conocer mejor el perfil de los estudiantes, puesto que este acceso masivo ha generado un cambio en los atributos de la población de estudiantes caracterizada por ser primera generación en sus familias en acceder a la educación superior, ser padres o madres, de mayor edad, pertenecientes a grupos étnicos, así como también provenientes de los sectores desfavorecidos de la sociedad (Araneda-Guirriman et al., 2018).

Por consiguiente, el proceso de transición hacia el contexto universitario se configura como un desafío para las instituciones de educación superior, puesto que un porcentaje de los alumnos que hacen ingreso a la educación postsecundaria no posee la preparación adecuada tanto en contenidos, como en orientación para las exigencias que amerita el contexto universitario (Tuero et al., 2017). Adquiere relevancia abordar el proceso de transición a la vida universitaria, entendido como las capacidades de los propios estudiantes para navegar este cambio (Gale y Parker, 2014) y el rol que tiene el programa de tutores pares en este proceso, puesto que contar con un tutor puede amortiguar las situaciones estresantes y conducir a una transición más exitosa en la universidad (Collings et al., 2015). En consecuencia, el programa de tutores pares tiene un rol clave en la transición a la educación superior de los estudiantes quienes se caracterizan además por presentar un perfil más diverso. 


\section{Programas de tutores}

En el contexto de la masificación en la matrícula de educación postsecundaria las instituciones de educación superior han realizado esfuerzos e iniciativas para hacer frente a los desafíos que este fenómeno conlleva siendo uno de estos el programa de tutores pares.

El programa de tutores pares es un esquema frecuente de encontrar en la educación superior y podría estar caracterizado de una diversidad de formas, no obstante, hay una serie de características en común de este programa que se sustentan en la creencia básica de la eficacia en el aprendizaje entre pares, junto con los beneficios del trabajo uno a uno o las experiencias en grupos pequeños. Es en este punto donde hay diferencias en términos de fines y objetivos, pues se abarcan una diversidad de estructuras grupales que reflejan estas diferencias y que conllevan además variedad de formas de interacción entre los participantes (Falchikov, 2001). Con relación a esto se encuentran a su vez los programas de mentoría, que son similares a los programas de tutores puesto que también abarcan procesos educacionales en la educación superior, pero con relaciones que pueden ser entre académicos y estudiantes, miembros del staff y estudiantes y de estudiantes con estudiantes (Lunsford et al., 2017), a diferencia con el programa de tutores que es entre pares, es decir solo entre estudiantes.

El programa de tutores es entendido como un mecanismo de soporte clave para los estudiantes de educación superior (Colvin, 2015), ya que este programa ofrece una aproximación para mejorar los resultados de aprendizaje (Pugatch y Wilson, 2018). La tutoría entre pares adquiere, por consiguiente, un sentido más orientado hacia la adquisición de habilidades de estudio, información relevante de todo ámbito educacional, orientación entre otros aspectos importantes para el desarrollo de nuevas habilidades cognitivas y transversales (Bustos-González-González, 2018). El programa de tutores pares ofrece, por ende, una aproximación hacia los cambios de hábitos de estudios, con la consecuente mejora de los resultados de los estudiantes en la educación superior (Pugatch y Wilson, 2018).

Las tutorías tienen como finalidad generar un refuerzo a los alumnos considerando las distintas realidades sociales y económicas que poseen los estudiantes al ingresar a la universidad, sobre todo para aquellos que provienen de los establecimientos públicos o subvencionados, dado que son quienes muestran mayores dificultades para adaptarse al nuevo contexto educacional universitario (Díaz y Morrison, 2016). La tutoría universitaria es un sistema intencional, programado y articulado que requiere de una estructura operativa, donde el docente universitario es un elemento central (López-Gómez et al., 2019).

Por consiguiente, el programa de tutorías pretende lograr una mayor inclusión y el desarrollo de oportunidades de todos los estudiantes que participen de este programa, no solo de los estudiantes que presentan problemas para alcanzar el éxito académico, sino que también de aquellos que demuestran mayor ventaja y que muchas veces no pueden desarrollar a plenitud sus potencialidades en un contexto muchas veces poco motivante y carente de desafíos (Bustos-González, 2018). Los resultados de un estudio efectuado por Xulu-Gama et al. (2018) concluyen que los estudiantes que se perciben a sí mismos como exitosos son aquellos que han podido incorporarse en la universidad de manera integral, aquellos que están socialmente conectados con sus compañeros y miembros de la comunidad académica, y que además se encuentran involucrados académicamente en sus asignaturas y que desarrollan una identidad como estudiantes al tener un sentido de pertinencia. El tutor debe de ser capaz de establecer cercanía a sus tutorados, ya que debe generar la capacidad de establecerse casi al mismo nivel con los tutorados, para que de esta manera los alumnos de cursos inferiores generen confianza hacia su tutor y con ello una mayor desenvoltura durante las sesiones de tutoría, consiguiendo de esta los aprendizajes esperados por el programa (Ortiz et al., 2015).

De acuerdo con Colvin (2015), se espera que el tutor par cumpla con dos roles principales. El primero hace referencia a ser un modelo de comportamiento que pueda ayudar a los estudiantes a lograr el éxito en sus clases. Los tutores que estaban acostumbrados a la posición de ser un "modelo" o de "sobresaliente", tenían menos dificultades para asumir ese rol. El otro rol que cumplen los tutores es ser un recurso para los estudiantes, en el sentido de que pueden recurrir a ellos los estudiantes para otorgarles ayuda y orientación. En esta línea, Bustos-González (2018), plantea que el estudiante que desempeñe el rol de tutor par debe contar con las siguientes cuatro características: 1) Responsabilidad: El tutor par debe ser responsable en toda labor que realice durante la acción tutorial; 2) Compromiso: Los tutores pares, al momento de asumir el rol de tutor, aceptan un compromiso el cual es fundamental a la hora de cumplir la labor; 3) Empatía: Un tutor es alguien que sabe escuchar a los demás; 4) Dedicación: Los tutores son mucho más que personas que intervienen en la adaptación del alumno, son mentores que ayudan a guiar al alumno de modo que pueda valerse por sí mismo en lo que continúe su vida universitaria.

Por consiguiente, la tutoría entre pares está recibiendo más atención debido a la creciente preocupación por la calidad del aprendizaje de los estudiantes y la disponibilidad de recursos (Kim, 2015), por tanto, también 
ha sido objeto de diversos estudios. Los estudios sobre las tutorías pares, predomina las metodologías más cualitativas, particularmente en su evaluación. En este sentido, se encuentra la retroalimentación informal de estudiantes y colegas, también la evaluación de los participantes, con el fin de ayudar en la reflexión (Falchikov, 2001). Los resultados de un estudio efectuado por Honkimäki y Tynjälä (2018) señalan que los estudiantes que recibieron tutoría grupal durante su primer año de estudio mostraron un grado mayor de autorregulación y cooperación que los estudiantes que no recibieron este apoyo. De igual forma, los resultados de un estudio efectuado por Cutrigh y Evans (2016) reconocen que el apoyo de tutores pares para las actividades de ingeniería, matemáticas y ciencias tuvo un impacto positivo en la retención de los alumnos de primer año que participaban del programa de beca de la Fundación Nacional de Ciencia, quienes al ser consultados a través de un cuestionario por dicha experiencia manifestaron que recomendarían participar de esta iniciativa a los nuevos estudiantes.

Por otra parte, desde la perspectiva teórica la tutoría entre pares se aborda desde la perspectiva de la integración y apoyo social, puesto que se puede establecer que la tutoría entre pares es un sistema de apoyo al centrarse en integrar a los estudiantes a la universidad más que proporcionarles instrucción adicional (Hall y Jaugietis, 2011). Esta teoría de la integración de los estudiantes ha sido también desarrollada por Tinto (1987) quien identifica la integración académica y social como clave para el éxito de los estudiantes en la educación superior.

\section{METODOLOGÍA}

Con el fin de analizar la percepción que tienen los estudiantes tutorados de las dimensiones del programa de tutores pares durante su primer año en una universidad estatal ubicada en el norte de Chile y su relación con el desempeño académico durante dicho año, se utilizó una metodología cuantitativa de corte descriptivo y trasversal. Vale precisar que por percepción en este trabajo se entiende al proceso subjetivo de adquirir, interpretar y organizar información sensorial, por tanto, un cuestionario que mide percepción tiene por finalidad identificar los procesos que subyacen en la forma en que los sujetos adquieren, interpretan, organizan y dan sentido al entorno en el que viven (Lavrakas, 2008).

Para recolectar la información se elaboró un cuestionario con escala de tipo Likert, las cuales derivaron tanto de la revisión de la literatura relacionadas con las tutorías como también del funcionamiento y las particularidades del programa de tutores pares de la universidad analizada en esta investigación. En el proceso de elaboración del cuestionario se consideró un proceso de validación con el fin de tener un instrumento más confiable. En este proceso participaron tres expertos y el proceso contó con las fases señaladas en la tabla 1.

Tabla 1: Fases de validación

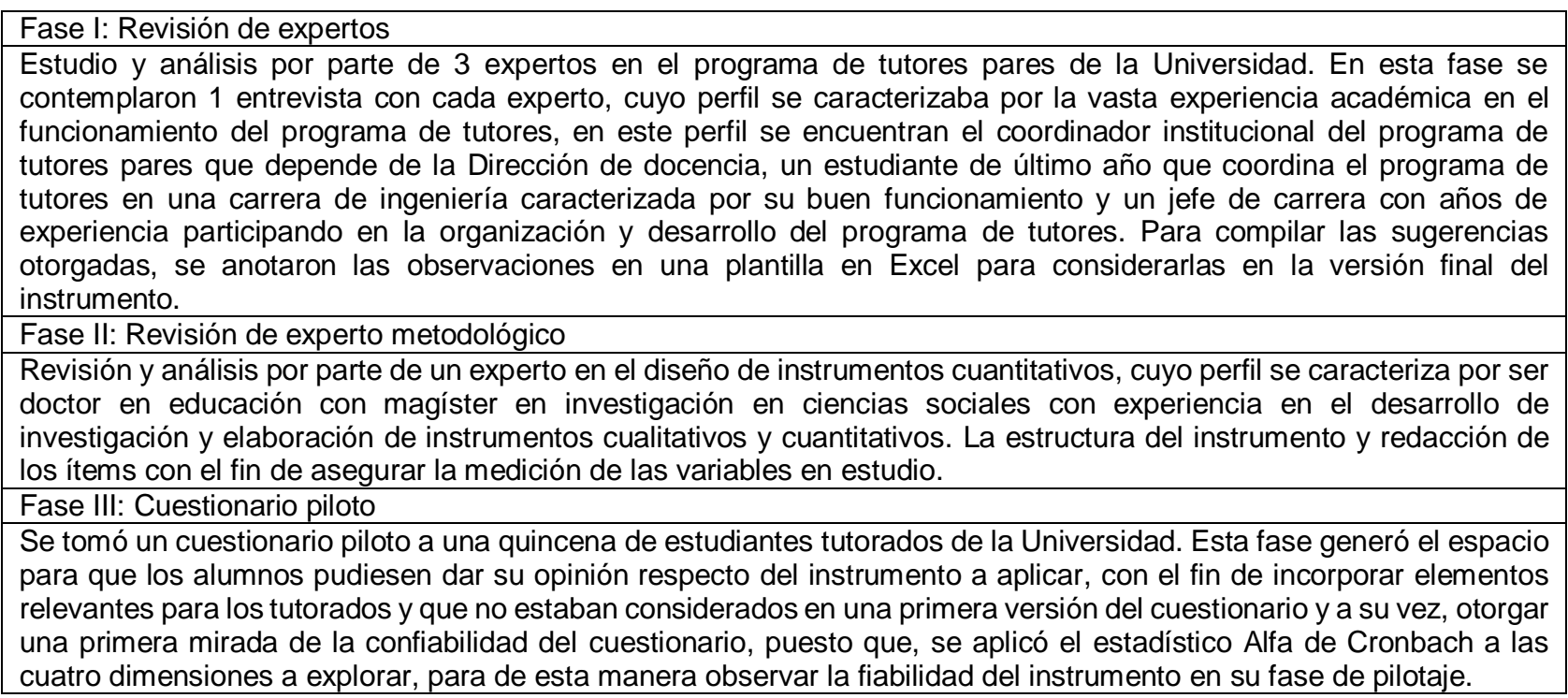

El instrumento finalmente quedó compuesto de 4 dimensiones, con un conjunto de ítems y se calculó el Alfa de Cronbach como se observa en la tabla 2 con el fin de evaluar la consistencia interna del cuestionario, puesto que este coeficiente refleja el grado en que los ítems miden una misma variable, es decir su homogeneidad (Quero, 2010). Como resultado de este proceso se eliminaron los ítems que no correspondían a la dimensión respectiva hasta que se logró un valor óptimo en el coeficiente superior a 0,8. 
Se utilizó la escala tipo Likert con valores desde el 1 al 7, donde el 1 es el máximo grado de desacuerdo y por contraparte el 7 es el máximo de acuerdo del ítem en cuestión. De acuerdo con lo señalado por Matas (2018) indica que al incrementarse las alternativas de cinco a siete en las escalas se aumentaba la confiabilidad del instrumento. De igual manera el instrumento constaba con una sección de comentarios, para que los tutorados señalaran los aspectos que no se estaban considerando entre los ítems y que eran relevantes de considerar según su perspectiva.

Las dimensiones utilizadas en el cuestionario fueron las siguientes: información, apoyo, infraestructura y tutor. Estas cuatro dimensiones se consideraron por ser claves para el correcto funcionamiento del programa de tutores pares en la universidad analizada. La dimensión información hace referencia a la información clave que entrega el programa que debe ser conocida por los estudiantes para que se adecúe a la universidad con el fin de mejorar su retención en la universidad. La dimensión apoyo considera la ayuda tanto psicoafectiva como académica que se entrega a los tutorados, contribución que resulta fundamental para la adaptación a la vida universitaria de los estudiantes que participan voluntariamente del programa. Con respecto a la infraestructura, esta dimensión se refiere al ambiente, las condiciones y la estructura que soporta la ejecución del programa de tutores en condiciones similares donde se desarrollan normalmente las clases. Por último, la dimensión del tutor, que engloba las características requeridas del tutor para desarrollar su labor en el programa, es decir, su preparación, vocación, empatía y disposición en el rol de acompañamiento de los estudiantes además de la cercanía con los profesores.

Como se observa en la tabla 2 las dimensiones antes mencionadas configuran el programa de tutorías entre pares en la universidad donde se llevó a cabo este estudio. Vale precisar que estas dimensiones se consideraron como variables en el estudio, dado que al interior de la propia universidad el funcionamiento del programa de tutores no es homogéneo y presenta variaciones en las carreras.

Tabla 2: Dimensiones y Alfa de Cronbach e ítems

Dimensión de Información

La información que se entregó fue útil respecto de los beneficios que otorga la Universidad.

Me sirvió para aprender sobre la carrera y su perfil de egreso.

Me sirvió para aprender sobre mi futuro campo laboral como futuro profesional.

Fue relevante para comprender como funcionan las asignaturas al inscribirlas y eliminarlas.

Me fue útil para conocer sobre los programas extracurriculares de la Universidad.

Me entregó información orientadora para desenvolverme de manera exitosa en la Universidad.

Me entregó información relevante para relacionarme con mis profesores.

Dimensión de Apoyo

En las tutorías aprendí métodos de aprendizaje o técnicas de estudio.

Me ayudó a entender y mejorar mis actitudes en la Universidad.

El programa de tutores fue un apoyo antes las dificultades académicas que tuve.

Me sentí parte de la Universidad gracias al programa de tutores.

El programa de tutores fue un apoyo para poder sobrellevar mis problemas personales.

Con las tutorías aprendí a ser más seguro de mí mismo.

Me ayudó a crear lazos con mis compañeros de Universidad.

Dimensión de Infraestructura

Las tutorías se realizaron en un horario acorde a las asignaturas que se cursaban.

El horario de las tutorías era respetado.

El espacio para realizar la tutoría permitía el trabajo en grupos.

El lugar donde se realizaba la tutoría contaba con el equipamiento necesario.

El lugar de sesión de tutoría contaba con la ventilación adecuada.

El estado de los inmuebles dentro del lugar de tutoría era eficiente.

El recinto donde se realizaban las sesiones de tutoría contenía acceso para personas con discapacidad.

Dimensión de Tutor

Mí tutor resolvía mis dudas en la tutoría.

Mí tutor tenía la disposición de resolver mis dudas fuera del horario de la tutoría.

Los temas a tratar en las diversas sesiones de tutoría fueron claves para entender la vida universitaria.

Mí tutor organizó tutorías donde se abordó como enfrentar las problemáticas personales.

Mí tutor demostraba empatía ante mis problemas.

Mi tutor tenía un trato cordial en las tutorías.

Mi tutor era respetuoso de mi espacio personal.

Alfa de

Cronbach

obtenido

$\alpha=0,933$ 
Con el fin de identificar si existe la relación entre la percepción de las dimensiones del programa de tutores pares y el desempeño académico de los estudiantes que en su primer año universitario que participaron como tutorados en este programa se utilizaron como proxy de desempeño académico la aprobación de asignaturas durante ese año de universidad y la cantidad de asignaturas reprobadas en caso de corresponder. Ambas preguntas se seleccionaron por ser de fácil respuesta y por no requerir un excesivo trabajo de memoria por parte de los estudiantes. Asimismo, la utilización de dicho proxy coincide con lo establecido por Adejo y Connolly (2017) quienes indican que se pueden identificar 6 aspectos que contribuyen a medir el desempeño de los estudiantes y que funcionan de manera individual y en conjunto para el éxito de los estudiantes los cuales son: dominio psicológico (autoeficiencia, logro, intereses); cognitivo (puntaje en los exámenes, habilidad intelectual); personalidad (motivación, estilo de aprendizaje, hábitos y tiempo de estudio); económico (ingresos, estado financiero principal); demográfico (edad, sexo, estad civil); y el aspecto institucional (programa del curso, ambiente de aprendizaje). Por tanto y de acuerdo con lo señalado anteriormente, el desempeño académico puede ser medido a través de la aprobación de asignaturas durante el primer año de universidad. Este aspecto hace referencia a la dimensión cognitiva del desempeño académico, que correspondería a una medición inicial y exploratoria consultada a través del cuestionario.

Cabe precisar que previa a la aplicación del cuestionario se entregó un consentimiento informado, de acuerdo con los estándares establecidos en los Comités de Ética nacionales, con el fin de que los estudiantes tutorados se informaran de los objetivos de la investigación y el tratamiento que se les daría a los datos recolectados, donde además se establecía que la participación era libre y voluntaria, en la cual se resguardaba la confidencialidad y el anonimato de la información recogida.

Vale precisar que el programa de tutores pares de la institución universitaria estudiada se inició el año 2013 con el propósito de acompañar a los estudiantes de reciente ingreso a la universidad en los procesos de inclusión académica con el fin de disminuir las causales potenciales de deserción. Para este fin existe un proceso formal de selección de los nuevos tutores pares que consideran aspectos académicos y también las habilidades psicoafectivas de los postulantes. Este proceso es realizado por la coordinación institucional del programa dependiente de la Dirección de Docencia. Semestralmente se elige una cantidad de tutores dependiente del número de matriculados que tiene cada carrera a una razón de 20-25 alumnos de primer año por cada tutor par.

Al inicio de cada período semestral se realizan sesiones de capacitación para los nuevos tutores pares que ingresan al programa. Además, periódicamente durante el semestre académico, se llevan a cabo reuniones de coordinación y de seguimiento de resultados a cargo de la coordinación institucional del programa. Por tratarse de un programa extracurricular para los alumnos nuevos no existe la obligación de participar. No obstante aquello, se efectúa un seguimiento de los nuevos alumnos desde el momento en que realizan el proceso de matrícula en adelante, para motivarlos a participar en el programa. La participación del Jefe de Carrera en las actividades de los tutores pares valida el accionar del programa de tutores pares ante los nuevos alumnos. Asimismo, existe un marco normativo formalizado debidamente por un acto administrativo, documento que establece la creación del programa de tutores pares, su reglamentación, y los procesos de postulación de tutores, la ejecución del programa y el cierre del mismo. El proceso de cierre considera una evaluación de la labor efectuada por los tutores pares en los siguientes tres componentes: Evaluación de la coordinación del programa, cuestionario de satisfacción de los tutorados y cuestionario de satisfacción del Jefe de Carrera.

Con relación a la población de estudio se considera a los alumnos que fueron tutorados a lo menos por un semestre académico, pero que ingresaron a la casa de estudios superiores dentro de los años 2015, 2016 y 2017 a las siguientes facultades: Ingeniería, Ciencias de la salud y Ciencias sociales y jurídicas. Se consideraron sólo estas tres facultades, ya que en ellas se concentra la mayor cantidad de alumnos de la institución. Para la obtención de una muestra se trabajó con un muestreo no probabilístico, puesto que no existía un listado confiable con todos los estudiantes que participaron del programa. El muestreo fue además por cuotas, con el fin de mantener la proporcionalidad de las facultades analizadas, para lo cual se consideraron las matrículas de las facultades del año 2018, donde primó el criterio de la accesibilidad y la pertinencia de los estudiantes que participaron del programa. La muestra estuvo finalmente compuesta por un total de 225 alumnos que cumplieron con las condiciones antes mencionadas.

Una vez aplicadas los cuestionarios fueron tabulados en el programa estadístico SPSS. Previo al análisis se efectuó la depuración de la base de datos y se realizaron análisis estadísticos descriptivos y bivariado como es la prueba del Chi Cuadrado, estadígrafo que permite contrastar dos variables categóricas, pertinente para este estudio para contrastar las hipótesis de observar si son independientes o si están relacionadas ambas variables, es decir, desempeño académico medido con la aprobación de asignaturas (variable dicotómica: sílno) y cada una de las dimensiones que configuran el programa de tutores pares de la universidad analizada: 
información, apoyo, infraestructura y tutor, cuyas categorías corresponden a la percepción medida a través de los grados de acuerdo o desacuerdo para cada una de las afirmaciones que componen la dimensión.

Una vez calculado el valor de cada dimensión se procede a la categorización de las respuestas en tres alternativas: Alto grado de acuerdo, es decir una percepción positiva de la dimensión, indiferente y un bajo grado de acuerdo, o sea una percepción más negativa de la dimensión. Desempeño académico además se mide por el número de asignaturas reprobadas, siendo analizada esta variable a través de un análisis bivariado con correlaciones de Pearson. A continuación, se presentan los resultados.

\section{RESULTADOS}

Del total de tutorados consultados el $57,8 \%$ son mujeres y un $42,2 \%$ hombres en el total de la muestra, de igual manera la mayoría de estos estaban en un rango de edad entre los 18 a los 20 años, en específico un $70,1 \%$ del total de la muestra. Un $26 \%$ corresponde a la Facultad de Ingeniería, un $31 \%$ a la Facultad de Ciencias Sociales y un $42 \%$ a la Facultad de Ciencias de la Salud.

Tabla 3: Hipótesis nulas y alternativas de la prueba no paramétrica

\begin{tabular}{|c|l|l|}
\hline Dimensión & \multicolumn{1}{|c|}{ Hipótesis nula } & \multicolumn{1}{c|}{ Hipótesis alternativa } \\
\hline \multirow{3}{*}{ Información } & $\begin{array}{l}\text { No existe relación entre la dimensión de } \\
\text { información y el desempeño académico } \\
\text { de los tutorados durante su primer año } \\
\text { en la Universidad. }\end{array}$ & $\begin{array}{l}\text { Existe relación estadísticamente significativa entre la } \\
\text { dimensión de información y el desempeño académico } \\
\text { de los tutorados durante su primer año en la } \\
\text { Universidad. }\end{array}$ \\
\hline \multirow{5}{*}{ Apoyo } & $\begin{array}{l}\text { No existe relación entre la dimensión de } \\
\text { apoyo y el desempeño académico de los } \\
\text { tutorados durante su primer año en la } \\
\text { Universidad. }\end{array}$ & $\begin{array}{l}\text { Existe relación estadísticamente significativa entre la } \\
\text { dimensión de apoyo y el desempeño académico de los } \\
\text { tutorados durante su primer año en la Universidad. }\end{array}$ \\
\hline \multirow{5}{*}{ Tutoraestructura } & $\begin{array}{l}\text { No existe relación entre la dimensión } \\
\text { infraestructura y el desempeño } \\
\text { académico de los tutorados durante su } \\
\text { primer año en la Universidad. }\end{array}$ & $\begin{array}{l}\text { Existe relación estadísticamente significativa entre la la } \\
\text { dimensión de infraestructura y el desempeño académico } \\
\text { de los tutorados durante su primer año en la } \\
\text { Universidad. }\end{array}$ \\
\hline & $\begin{array}{l}\text { No existe relación entre la dimensión de } \\
\text { tutor y el desempeño académico de los } \\
\text { tutorados durante su primer año en la la } \\
\text { Universidad. }\end{array}$ & $\begin{array}{l}\text { Existe relación estadísticamente significativa entre la } \\
\text { dimensión que evalúa la percepción del tutorado sobre } \\
\text { él tutor y el desempeño académico de los tutorados } \\
\text { durante su primer año en la Universidad. }\end{array}$ \\
\hline
\end{tabular}

El análisis estadístico Chi cuadrado, permitió determinar si existía relación significativa entre las 2 variables categóricas (Franke et al., 2012), de acuerdo con las pruebas de hipótesis señaladas en la tabla 3 con el fin de observar la relación entre el desempeño académico de los estudiantes tutorados medidos a través de la reprobación de alguna asignatura durante el primer año de universidad, cuyas categorías son sí y no y las dimensiones que componen la evaluación del programa de tutores pares. El análisis se realizó para cada una de las dimensiones señaladas, en la tabla 4 donde se procede a exponer los resultados del Chi Cuadrado que resultó en cada una de las posibles relaciones establecidas.

Tabla 4: Valores del Chi-cuadrado de Pearson según las dimensiones y la reprobación de los tutorados

\begin{tabular}{|c|c|c|c|}
\hline \multirow{4}{*}{$\begin{array}{c}\text { ¿Reprobaste alguna } \\
\text { asignatura en primer } \\
\text { año? }\end{array}$} & Dimensión & Valor Chi $^{2}$ & $\begin{array}{c}\text { Valor de la } \\
\text { Significancia }\end{array}$ \\
\cline { 2 - 4 } Sí/No & Información & 2,953 & 0,228 \\
\cline { 2 - 4 } & Apoyo & 8,253 & 0,016 \\
\cline { 2 - 4 } & Infraestructura & 1,152 & 0,562 \\
\cline { 2 - 4 } & Tutor & 5,151 & 0,076 \\
\hline
\end{tabular}

Como se aprecia en la tabla 4 solo en la dimensión de apoyo resultó ser significativa $(p<0,05)$ y por ende, en dicha dimensión se apoya la hipótesis alternativa y se rechaza la hipótesis nula, puesto que sí existe una relación estadísticamente significativa entre la reprobación y la percepción de apoyo. En este sentido, existe una percepción positiva del apoyo recibido. Lo anterior coincide con los planteamientos de Colver y Fry (2016) quienes señalan que los estudiantes que recibieron tutoría de pares tuvieron puntuaciones significativamente más altas de conocimiento en comparación a los estudiantes que solo estudian o leen, obteniendo además mayores puntuaciones que otros estudiantes. En esta misma línea se encuentra lo planteado por Clarence (2018) quien establece que el programa de tutoría entre pares tiene una larga historia en los espacios de apoyo académico en las universidades, como programas de instrucción complementarios. En este contexto, la tutoría entre pares se ha movido durante el último tiempo hacia la enseñanza y el aprendizaje convencionales y se ha transformado en una necesidad académica en estos espacios. La naturaleza de los 
compromisos de los estudiantes y los tutores en estos espacios es sobre compartir y co-construir conocimiento y desarrollar estudiantes más independientes, no obstante, la capacitación de los tutores es aún insuficiente para crear espacios de tutoría participativos e inclusivos.

Mientras que la relación entre el desempeño académico, medido a través de la aprobación de asignaturas durante el primer año de universidad con las tres dimensiones restantes no resultó ser significativa, por consiguiente, se rechazan las hipótesis alternativas, es decir que, para las dimensiones referidas a la percepción de la información, la infraestructura y el tutor del programa de tutores pares no se relacionan con el desempeño académico de los tutorados durante el primer año en la Universidad.

Finalmente, para optimizar la lectura del comportamiento de las variables trabajadas en la investigación, se considera un análisis de correlación de Pearson entre las dimensiones expuestas en la tabla 5 y la cantidad de asignaturas reprobadas por los estudiantes de la muestra.

Tabla 5: Correlaciones bivariadas de Pearson.

\begin{tabular}{|l|c|}
\hline & Reprobación de asignatura \\
\hline Reprobación de asignatura & 1 \\
\hline Información & $-0,107$ \\
\hline Apoyo & $-0,093$ \\
\hline Infraestructura & $-0,034$ \\
\hline Tutor & $-0,154^{*}$ \\
\hline
\end{tabular}

Los resultados obtenidos bajo el análisis de correlación de Pearson bivariada observados en la tabla 5 demuestran que la variable dependiente al número de asignaturas reprobadas durante el primer año, solo una de las cuatro dimensiones, la referida a la percepción del tutor resultó tener una relación significativa la cual posee en específico un $R$ de $-0,154$, lo que indica una relación débil, pero significativa $(p<0,05)$ entre ambas variables e inversamente proporcional. En este sentido, la variable independiente del tutor explica solo un $1,9 \%$ de la varianza ( $R$ cuadrado ajustado 0,019 ). Es decir, una percepción más positiva del perfil del tutor implica un valor negativo en la reprobación de asignaturas en primer año, en consecuencia, menos asignaturas reprobadas en dicho período. La importancia del tutor en el desempeño académico de los estudiantes coincide con los resultados encontrados por Hutchison (2018), quien señala que dada la relevancia que tiene el tutor es importante que se considere qué rol va a desempeñar en cada sesión de tutoría, es decir, si será entrenador, facilitador o coach y que esto quede claro en los estudiantes.

Se puede establecer, por tanto, que el tutor par provee un servicio relevante para los estudiantes, por ende, resulta fundamental el entrenamiento que reciben los tutores pares para tener éxito, donde los tutores crean, piensen y se identifiquen con su rol, ya que cuando ellos comienzan su interacción con los estudiantes, como pares, ellos deben pensar su rol en ese contexto específico de la interacción (Colvin, 2015). La importancia de las características de la empatía, la disposición y el respeto de parte del tutor coincide con los resultados encontrados en otros estudios donde se destacan las características personales que debiera tener el tutor, tales como la empatía, autenticidad, madurez, responsabilidad y sociabilidad (López-Gómez et al., 2019), elementos que son reconocidos como relevantes por los alumnos tutorados.

\section{DISCUSIÓN FINAL}

Los cambios experimentados en los sistemas de educación superior durante las últimas décadas han traído consigo no solo una variedad y expansión de las instituciones de educación superior, sino que también ha implicado una masificación de la matrícula y una diversificación del perfil de estudiantes que ingresa (O Shea, 2016; Araneda-Guirriman et al., 2018). Este último punto se configura como un desafío para las universidades, las que se han visto en la necesidad de definir estrategias que se adapten a las necesidades de este nuevo perfil de estudiantes.

Una de las estrategias aplicadas en las universidades para facilitar la adaptación e inserción a la vida universitaria de los estudiantes en primer año es el programa de tutores pares, iniciativa que destaca por apoyar a los estudiantes en su transición desde la educación secundaria a la terciaria. En este sentido, la percepción positiva se relaciona con una menor cantidad de asignaturas reprobadas en primer año de estudiantes. En este caso estudiado el apoyo se observa con técnicas de estudios, ayuda ente las dificultades académicas y también ante los problemas personales, que además conlleva a un sentimiento de pertenencia a la universidad al facilitar la generación de lazos entre los compañeros. Los anterior coincide con los resultados alcanzados por Made et al., (2019) quienes encontraron en el programa de tutores de la Humboldt State University no solo redujo la brecha de logros en los estudiantes que participaron de este, sino que también disminuyó la tasa de fracaso. 
El tutor, por consiguiente, juega un rol fundamental para asegurar el bienestar emocional en el proceso de adaptación del estudiante que vive la transición hacia la educación terciaria. Se puede destacar que un buen apoyo genera que el alumno de primer año en la universidad tenga una mayor percepción favorable respecto a su carrera y su institución. Dicha percepción positiva se traduce al mediano plazo como un buen rendimiento académico y, por ende, en una menor posibilidad de deserción. En consecuencia, el tutor se configura como un actor clave para la transición de los estudiantes de primer año, ya que ellos trabajan directamente con los alumnos en un nivel de pares al ser también estudiantes, situación que facilita la adaptación a los desafíos y nuevas responsabilidades que implica ser estudiantes universitarios. Por ende, es de suma importancia, que los tutores de las instituciones sean capaces de generar un apoyo constante y efectivo a los estudiantes de primer año, ya que finalmente esto repercute no solo en su adaptación, sino que también en su desempeño académico.

\section{LIMITACIONES}

Los resultados presentados corresponden a un estudio de caso realizado en una universidad, por lo tanto, no son generalizables ni necesariamente representativos del sistema de educación superior chileno. Asimismo, estos resultados alcanzados corresponden a una fase exploratoria que aborda en una primera aproximación la relación entre la percepción de las dimensiones del programa de tutores pares con en el desempeño académico de los estudiantes de primer año de universidad que participaron de dicho programa. Para profundizar en los resultados alcanzados, en una próxima investigación debiera evaluarse el impacto del programa de tutores sobre el desempeño académico considerando como grupo de control a los estudiantes de primer año que no participaron de este programa.

\section{CONCLUSIONES}

De acuerdo al trabajo presentado y a los resultados obtenidos, se pueden plantear las siguientes conclusiones principales:

1. La implementación del programa de tutores pares es en la actualidad una estrategia frecuentemente utilizada en las universidades con el fin de apoyar la transición de los estudiantes desde la educación secundaria a la educación superior a través del trabajo entre pares, donde el tutor tiene un rol fundamental en el desarrollo de este programa.

2. Existe una diversidad y también matices en el diseño e implementación del programa de tutores pares en las universidades, en el caso de la universidad analizada destacan cuatro dimensiones del programa que lo componen: la información entregada, el apoyo que otorga el tutor, la infraestructura que soporta la ejecución del programa y el tutor.

3. Se destaca la importancia que tiene el apoyo recibido por el programa en la percepción de los jóvenes tutorados en el buen desempeño académico, medido por la aprobación de asignaturas, alcanzado por ellos en el primer año de universidad. En esta dimensión de apoyo del programa de tutores pares hace referencia a la entrega de métodos de estudio, orientación respecto a una mejora en las actitudes para sentirse parte de la universidad, orientación ante las dificultades académicas, ayuda para establecer redes entre sus pares, y también apoyo en aspectos de personalidad. Por lo tanto, es una dimensión valorada por parte de los estudiantes que participaron del programa.

4. Otra dimensión del programa de tutores pares que destaca positivamente en la percepción de los estudiantes es el tutor, en específico el rol que este tiene, donde resalta la disposición para resolver dudas, las temáticas de interés que seleccionaba para facilitar el entendimiento de la vida universitaria, la empatía, el respeto. La percepción que manifestaron los tutorados se relaciona de manera significativa e inversa con el número de asignaturas reprobadas.

5. Vale precisar que al ser un programa de participación voluntaria se dificulta conocer la real magnitud de la relación entre sus dimensiones y el desempeño académico de los estudiantes de primer año.

6. En consecuencia, para el desarrollo del programa de tutores pares destacan en importancia el apoyo que este programa brinda a los estudiantes y el tutor que ejecuta finalmente el programa. Por consiguiente, ambos aspectos deben ser considerados al momento de definir acciones y políticas institucionales para su fortalecimiento en pos de contribuir de manera positiva a la transición y adaptación a la vida universitaria y en particular al desempeño académico de los estudiantes.

\section{AGRADECIMIENTOS}

Los autores agradecen el patrocinio de la Comisión Nacional de Investigación Científica y Tecnológica de Chile (CONICYT) a través del proyecto del Fondo Nacional de Desarrollo Científico y Tecnológico (FONDECYT) Regular № 1171276: "Estrategias Académicas para el Nuevo Perfil de Estudiantes: Un Análisis desde las Universidades Chilenas" 


\section{REFERENCIAS}

Adejo, O. W., y Connolly, T., An Integrated System Framework for Predicting Students' Academic Performance in Higher Educational Institutions, https://doi.org/10.5121/ijcsit.2017.93013, International Journal of Computer Science and Information Technology, 9(3), 149-157 (2017).

Altbach, P.G., Globalization and Forces for Change in Higher Education, https://doi.org/10.6017/ihe.2008.50.7997, International Higher Education, (50), 2-4 (2015).

Araneda-Guirriman, C., Gairín, J., Pedraja-Rejas, L. y Rodríguez-Ponce, R., Percepciones sobre el Perfil del Estudiante Universitario en el Contexto de la Educación Superior de Masas: Aproximaciones desde Chile, Interciencia, 43(12), 864870 (2018).

Bowles, A., R. Fisher, R., y otros tres autores, Staying the Distance: Students' Perceptions of Enablers of Transition to Higher Education, https://doi.org/10.1080/07294360.2013.832157, Higher Education Research \& Development, 33(2), 212-225 (2014).

Bustos-González, R. Desarrollo de Competencias Genéricas en Estudiantes que se Desempeñan como Tutores Pares en la Universidad, Revista Colombiana de Educación, (75), 99-117 (2018).

Clarence, S. Peer Tutors As Learning and Teaching Partners: a Cumulative Approach to Building Peer Tutoring Capacity in Higher Education, https://doi.org/10.14426/cristal.v4i1.69, Critical Studies in Teaching and Learning, 4(1), 39-54 (2016).

Collings, R., Swanson, V., y Watkins, R., Peer mentoring during the transition to university: Assessing the usage of a formal scheme within the UK, https://doi.org/10.1080/03075079.2015.1007939, Studies in Higher Education, 41(11), 1995-2010 (2016).

Colver, M., y Fry, T., Evidence to Support Peer Tutoring Programs at the Undergraduate Level, https://doi.org/10.1080/10790195.2015.1075446, Journal of College Reading and Learning, 46(1), 16-41 (2016).

Colvin, J.W., Peer Mentoring and Tutoring in Higher Education, Exploring Learning \& Teaching in Higher Education, $1^{\mathrm{a}}$ Ed., pp 207-229, Springer, Berlin, Alemania (2015).

Cotton, D., Nash, T., y Kneale, P., Supporting the Retention of Non-traditional Students in Higher Education Using a Resilience Framework, https://doi.org/10.1177/1474904116652629, European Educational Research Journal, 16(1), 6279 (2017).

Cuenca, R., Las Promesas Democráticas de la Universidad Latinoamericana: Balance de un Centenario, El Papel Estratégico de la Educación Superior en el Desarrollo Sostenible de América Latina y el Caribe, 1aㅡ. Ed., pp 31-52, UNESCO-IESALC, Caracas, Venezuela y UNC, Córdoba, Argentina (2018).

Díaz, C.P., y Morrison, R., Tutorías en Educación Superior: Posibilidades para la Terapia Ocupacional, Revista TOG (A Coruña), 13(23) (2016).

Eckert, K.B., y Suénaga, R., Análisis de Deserción-Permanencia de Estudiantes Universitarios Utilizando Técnica de Clasificación en Minería de Datos, https://doi.org/10.4067/S0718-50062015000500002, Formación Universitaria, 8(5), 0312 (2015).

Franke, T.M., Ho, T., y Christie, C.A., The Chi-square Test: Often Used and More Often Misinterpreted, https://doi.org/10.1177/1098214011426594, American Journal of Evaluation, 33(3), 448-458 (2012).

Franke, T.M., Ho, T. y Christie, C.A., The Chi-square Test: Often Used and More Often Misinterpreted, doi: 10.1177/1098214011426594, American Journal of Evaluation, 33(3), 448-458 (2012).

Gale, T. y Parker, S., Navigating Change: a Typology of Student Transition in Higher Education, doi: 10.1080/03075079.2012.721351, Studies in Higher Education, 39(5), 734-753 (2014).

Hall, R., y Jaugietis, Z., Developing Peer Mentoring Through Evaluation, https://doi.org/10.1007/s10755-010-9156-6, Innovative Higher Education, 36(1), 41-52 (2011).

Kim, M.M., Peer Tutoring at Colleges and Universities, College and University, 90(4), 2-7 (2015).

Lavrakas, P.J., Encyclopedia of Survey Research Methods, $1^{\text {a }}$ Ed., vol. 1 y 2, Sage Publications, Thousand Oaks, USA (2008).

López-Gómez, E., Leví-Orta, G., Medina, A., y Ramos-Méndez, E., Dimensions of University Tutoring: A Psychometric Study, https://doi.org/10.1080/0309877X.2019.1571174, Journal of Further and Higher Education, 1-19 (2019).

Lunsford, L.G., Crisp G., Dolan, E.L., y Wuetherick, B., Mentoring in Higher Education, The SAGE Handbook of Mentoring, 316-334 (2017).

Marginson, S., The Worldwide Trend to High Participation Higher Education: Dynamics of Social Stratification in Inclusive Systems, https://doi.org/10.1007/s10734-016-0016-x, Higher Education, 72(4), 413-434 (2016).

Matas, A., Diseño del Formato de Escalas Tipo Likert: Un Estado de la Cuestión, https://doi.org/10.24320/redie.2018.20.1.1347, Revista electrónica de investigación educativa, 20(1), 38-47 (2018).

Mayhew, M.J., Rockenbach, A.N., y otros cinco autores, How College Affects Students: 21st Century Evidence that Higher Education Works, 1a Ed., vol. 3, Jossey-Bass, San Francisco, USA (2016). 
Munizaga, F.R., Cifuentes, M.B., y Beltrán, A.J., Retención y Abandono Estudiantil en la Educación Superior Universitaria en América Latina y el Caribe: Una Revisión Sistemática, https://doi.org/10.14507/epaa.26.3348, Archivos Analíticos de Políticas Educativas, 26(61), 1-32 (2018).

OECD, Education at a Glance 2018: OECD Indicators, 1aㅡ., OECD Publishing, París, Francia (2018).

OCDE, Evaluaciones de Políticas Nacionales de Educación: Educación en Chile, $1^{\text {a }}$ Ed., OECD Publishing, París, Francia y Fundación SM, Ciudad de México, México (2017).

Ortiz, D., Gaete, R., y Villarroel, V., ¿Es la Tutoría de Pares una Estrategia para Evitar la Deserción?, Congresos Clabes (2015).

O'Shea, S., First-In-Family Learners and Higher Education: Negotiating the 'Silences' of University Transition and Participation, Higher Education Research and Development, 3, 5-23 (2016).

Pugatch, T., y Wilson, N., Nudging Study Habits: A Field Experiment on Peer Tutoring in Higher Education, https://doi.org/10.1016/j.econedurev.2017.11.003, Economics of Education Review, 62, 151-161 (2018).

Quero, M., Confiabilidad y Coeficiente Alpha de Cronbach, Telos, 12(2), 248-252 (2010).

Ramírez, P.E., y Grandón, E.E., Predicción de la Deserción Académica en una Universidad Pública Chilena a través de la Clasificación Basada en Árboles de Decisión con Parámetros Optimizados, Formación Universitaria, 11(3), 3-10 (2018).

Rizvi, F., Realizing the Benefits of Massification, https://doi.org/10.6017/ihe.2018.0.10562, International Higher Education, 94, 18-19 (2018).

Schuetze, H.G., y Slowey, M., Participation and Exclusion: A Comparative Analysis of Non-traditional Students and Lifelong Learners, https://doi.org/10.1023/A:1019898114335, Higher Education, 44(3-4), 309-327 (2002).

Scott, D., Hughes, G., y otros cuatro autores, Learning Transitions in Higher Education, 1a Ed., Palgrave Macmillan UK, Londres, Inglaterra (2014).

SIES, Informe de Retención de 1er Año de Pregrado Cohortes 2013-2017 (2018).

Tinto, V., Leaving College: Rethinking the Causes and Cures of Student Attrition, 1․ Ed., University Of Chicago Press, Chicago, USA (1987).

Trowler, V., Transit and Transition: Student Identity and the Contested Landscape of Higher Education, Identities, Youth and Belonging, 1aㅡ. Ed., Palgrave Macmillan, Cham, Suiza (2019).

Tuero, E., Cervero, A., y otros tres autores, La Transición a la Universidad: Eficacia de un Programa de Orientación en Bachillerato Apoyado en las TIC, Congresos Clabes (2017).

Unterhalter, E., Global: What is Wrong with Global Inequality in Higher Education?, https://doi.org/10.1007/978-94-6351044-8_1, Understanding Global Higher Education, (205), 1-7 (2017). 